\title{
Jovanović, Željko (2020): Twentieth-Century Sephardic Authors from the Former Yugoslavia. A Judeo-Spanish Tradition, Cambridge, Legenda (Studies in Hispanic and Lusophone Cultures, 41), 208 pp.
}

El libro que aquí se reseña analiza un aspecto de la historia de los sefardíes - la que corresponde a los siglos XIX y XX y a la antigua Yugoslavia - al que la crítica no ha prestado hasta ahora demasiada atención. Estructurado en tres partes, el estudio de Jovanović empieza centrándose en la labor de dos escritores anteriores a la Segunda Guerra Mundial, el serbio Haim Samuilo Davičo (1854-1918) y la escritora bosnia Laura Papo (1891-1942). Ambos escriben en un mismo contexto histórico, el de la crisis de la vieja cultura sefardí que empezaba a desaparecer como consecuencia de la modernización de los Balcanes. Pero una y otro reaccionan de manera diferente ante esa situación: Davičo es un decidido partidario de incorporar su país a Occidente y busca solo preservar la memoria de una cultura cuya desaparición se le aparece como inevitable; Papo, por el contrario, aspira a revitalizarla. En consecuencia, ni la lengua ni el público son los mismos para ambos autores: Davičo busca un público amplio y traduce casi siempre al serbio los materiales sefardíes con los que trabaja, mientras que Papo escribe para un público más restringido y no abandona prácticamente nunca el judeo-español. En lo que sí coinciden ambos es en la forma de aprovechar ese legado. Ni una ni otro se limitan a recoger cuentos, romances o refranes, sino que los incorporan a sus obras originales (narrativas, fundamentalmente, en el caso de Davičo y teatrales en el de Papo). Es aquí donde se encuentran algunas de las mejores páginas del libro. Los análisis de Jovanović muestran cómo los dos escritores consiguen acomodar los materiales folclóricos a sus propósitos y su ideología solo mediante mínimos retoques $\mathrm{y}$, sobre todo, mediante el contexto en el que aparecen. Así, Davičo incluye el romance de Landarico en su relato Buena, pero traduciéndolo al serbio, de acuerdo con su forma habitual de tratar los textos sefardíes. Además, los comentarios compasivos de los personajes del cuento que escuchan el romance invitan a interpretar la condena de la reina no como el merecido castigo de una adúltera, sino como un alegato contra los matrimonios impuestos por presiones familiares. Por el contrario, la madre de familia que canta el romance en la obra de Laura Papo Avía de ser, mantiene tanto la lengua como la interpretación tradicional del desenlace: la reina es castigada por su adulterio, aunque la madre aprovecha también para prevenir a sus hijas contra la maldad de los hombres. Un caso especialmente llamativo es el del breve relato Ženske šale (Los engaños de las mujeres), que Davičo publicó en 1885 presentándolo como un relato folclórico, pero que, en realidad, es una traducción, más o menos libre, de Los tres maridos burlados de Tirso de Molina.

La segunda parte del libro vuelve a estructurarse en torno a una mujer, Gina Camhy (1909-1990) y un hombre, Isak Papo (1912-1996), ambos nacidos en Bosnia. Tras el Holocausto y la desaparición de comunidades enteras, se hacía más acuciante la tarea de salvaguardar las señas de identidad de la cultura sefardí. Camhy lo hace desde periódicos como Le Judaïsme Sephardi, asociados a los círculos pro-sefardíes de París, en tanto que Papo permanece en Bosnia y desarrolla allí su trabajo como investigador. 
Ambos coinciden en utilizar el judeo-español como lengua de expresión y trabajan sobre sus recuerdos personales de infancia. Los dos rescatan así textos tradicionales (sobre todo relatos en prosa) incorporándolos con frecuencia a sus descripciones de las viejas formas de vida sefardíes. La perspectiva de género es aquí fundamental, porque Camhy escoge en sus artículos los temas favoritos de las escritoras sefardíes, es decir, los relacionados con la casa, la comida y la preparación de las fiestas: Purim en mi civdad, Los aparejos de Pesah o El guisado de mi madre. Papo ignora esos temas y describe tipos característicos de la comunidad o recoge sin más narraciones folclóricas.

De nuevo, Jovanović desciende aquí con pericia al análisis de los textos concretos. Quizá el de mayor interés es Il čuflet dil pastor, que Isak Papo escribió probablemente no como resultado de un trabajo de campo, sino sacándolo de sus propios recuerdos. El cuento es una versión del conocido relato de las orejas de burro del rey Midas, pero se combina con otros motivos folclóricos, algunos específicos de la antigua Yugoslavia, que Jovanović rastrea minuciosamente.

La tercera parte de la obra difiere en su planteamiento de las dos primeras. En lugar de estructurar su exposición en torno a una pareja de escritores, el autor persigue la fortuna entre los sefardíes de un personaje, Djohá, bien conocido en muchos lugares de la cuenca mediterránea como encarnación del trickster o tonto-listo. Su origen debe buscarse en el mundo árabe de la Edad Media y varios investigadores habían defendido ya que los relatos y refranes centrados en el personaje debieron de circular también por Al-Andalus. Jovanović aporta nuevos argumentos para confirmar esa idea y supone que los judíos, tras asumir esa herencia, se la llevaron al abandonar la Península a finales del siglo XV. No obstante, el corpus de cuentos de Djohá en la antigua Yugoslavia es más bien limitado. En los años finales del siglo XIX y primera mitad del XX se reduce a una docena cuentos, y en la segunda mitad se limita a algo más de veinte relatos, publicados casi en su totalidad por Matilda Koén-Sarano en varios libros aparecidos a caballo entre el siglo XX y el XXI.

En el estudio de esos relatos, el autor vuelve a plantear una de las cuestiones centrales de su libro, la de la forma y el propósito con los que se recogen y publican esos materiales tradicionales. El caso de Žak Konfino es paradigmático: en 1934 publica un cuento que, a pesar de tener como protagonista a Djohá y de recurrir a varios motivos folclóricos, parece una invención del propio Konfino. En 1957, tras el Holocausto, Konfino publica otro relato protagonizado por el mismo personaje, pero en este caso se trata de un «true folktale», como lo define Jovanović, que el autor probablemente recordaba de memoria.

Las páginas finales del libro, dedicadas a las varias publicaciones de KoénSarano sobre Djohá, sitúan a Serbia y Bosnia en un contexto más amplio, pues el autor toma en consideración todos los relatos centrados en el personaje, sea cual sea su procedencia geográfica. Tampoco aquí el paso de la oralidad a la escritura se produce sin distorsiones. Al menos en principio, Koén-Sarano se propone editar los cuentos dándoles, como ella misma dice, «una veste literaria» o «lustrándolos komo lustrí el tas de kovre». Esa premisa explica su recelo ante los cuentos obscenos, que finalmente se decide a publicar, si bien suprimiendo ciertas expresiones demasiado crudas o explícitas. Y de nuevo, la lengua que se escoge, judeo-español o inglés, es fundamental para determinar las intenciones de la recopiladora.

A lo largo de toda la obra, Jovanović vertebra su estudio en torno a varias parejas de opuestos, con frecuencia estrechamente relacionadas: antes y después del Holocausto, 
modernización y tradición, lengua serbia (o francesa o inglesa) frente a judeo-español, revitalización de una cultura en trance de desaparecer frente a su nostálgica conservación. La reiterada aplicación de esos esquemas binarios, si bien obliga a ciertas repeticiones, sirve para dar coherencia y claridad al conjunto. En su exposición, Jovanović aúna siempre el rigor positivista con la sutileza interpretativa: la riqueza de la información, el respeto a los hechos e incluso la atención a los mínimos detalles textuales no excluyen otras formas de análisis que, manejadas con cautela, permiten al autor construir un libro sólido y brillante, que arroja luz sobre muchas cuestiones: la oralidad y su relación con la escritura, la historia de las mujeres y de las minorías y, naturalmente, la pervivencia del legado hispánico más allá de los límites de la Península.

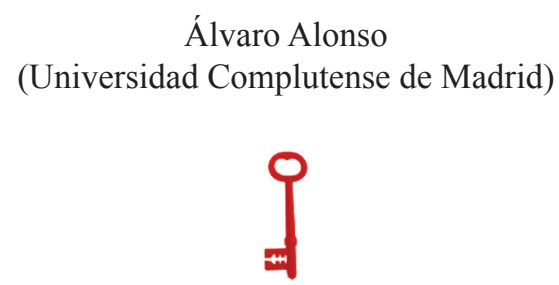

